\title{
The Application of ICT Techs (Mobile-assisted Language Learning, Gamification, and Virtual Reality) in Teaching English for Secondary School Students in Malaysia during COVID-19 Pandemic
}

\author{
Ali Sorayyaei Azar*, Nur Haslinda Iskandar Tan \\ School of Education and Social Sciences, Management \& Science University, 40100 Shah Alam, Malaysia
}

Received June 24, 2020; Revised October 1, 2020; Accepted November 7, 2020

\begin{abstract}
Cite This Paper in the following Citation Styles
(a): [1] Ali Sorayyaei Azar, Nur Haslinda Iskandar Tan, "The Application of ICT Techs (Mobile-assisted Language Learning, Gamification, and Virtual Reality) in Teaching English for Secondary School Students in Malaysia during COVID-19 Pandemic," Universal Journal of Educational Research, Vol. 8, No. 11C, pp. 55 - 63, 2020. DOI: 10.13189/ujer.2020.082307.
\end{abstract}

(b): Ali Sorayyaei Azar, Nur Haslinda Iskandar Tan (2020). The Application of ICT Techs (Mobile-assisted Language Learning, Gamification, and Virtual Reality) in Teaching English for Secondary School Students in Malaysia during COVID-19 Pandemic. Universal Journal of Educational Research, 8(11C), 55 - 63. DOI: 10.13189/ujer.2020.082307.

Copyright $(2020$ by authors, all rights reserved. Authors agree that this article remains permanently open access under the terms of the Creative Commons Attribution License 4.0 International License

\begin{abstract}
With the sudden changes caused by the ongoing worldwide pandemic in Malaysia and rapid progress in the educational learning system towards online learning, some teachers wondered about the application of technology in students' education and how it would impact their learning process. Therefore, the main objectives of this research are (1) to contextually understand the university interns' perception of ICT Techs (MALL, Gamification, and VR) in teaching English for secondary school students during the Covid-19 Pandemic in Malaysia, and (2) to determine which of these ICT Techs (MALL, Gamification, and VR) would be most preferred by the interns for teaching English to secondary school students in Malaysia. The research design for this study was quantitative and a web-based questionnaire was adapted from three articles (Mihaela Badea, 2015; Huseyin Oz, 2015; and Ali Rahimi, Niloofar Seyed Golshan \& Hooman Mohebi, 2013). The reliability test indicated a value of 0.866 with Cronbach's Alpha reliability statistic. From a total of 63 university interns selected from a private university in Malaysia, the results indicated that $38.1 \%$ chose MALL, 33\% chose Gamification, and 29\% chose VR, as their preferred technology to teach English for secondary school students during this Covid-19 Pandemic in Malaysia. Evidence
\end{abstract}

suggested that online learning can be more effective for students where they can control their own learning pace, compared to learning in a classroom environment. Thus, future English teachers should explore and apply innovative pedagogical methods in the teaching-learning process during pandemic outbreak in Malaysia, while contributing to the development of motivation, participation, and engagement among secondary school students in acquiring the English language.

Keywords Gamification, MALL, VR, COVID-19 Pandemic, Secondary School Students, English Language

\section{Introduction}

Coronavirus, also known as Covid-19 has been identified as a deadly infectious disease caused by severe acute respiratory syndrome along with some types of a common cold. Due to its rapid spread and extensive death caused, it has been declared a worldwide pandemic emergency. As a consequence of this outbreak, the first announcement of the Movement Control Order (MCO) was to have a lockdown throughout the states in Malaysia. 
This has impacted the education sector as throughout the pandemic crisis, schools have been temporarily shut down. As a result, the Ministry of Education has opted for online learning or e-learning with the students through technology or devices to facilitate communication in replacing classroom instructional learning.

Back in 1981, the Ministry of Education in Malaysia offered a course called the Instructional Systems Technology for the preservice teacher training program to improve the education system focusing on the teaching and learning process. Since then, many researchers have conducted studies on the implementation of 21st century technologies such as Virtual Reality, Gamification, and Mobile-assisted language learning (MALL) applications into developing and enhancing the students' English language.

Besides that, online games have influenced the lifestyles of kids, teenagers and even adults around the world. Researchers believe that applying gamification into education would not only motivate, but also increase students' focus on learning and their higher order thinking skills. According to researchers such as Roslina \& Azizah (2009), and Rafail Prodani, Silvja Çobani, Jozef Bushati, and Aigars Andersons (2020) the implementation of digital technologies in the education system is essential to suit the students' interests and expectations.

According to many researchers with regards to the use of mobile applications in language learning, this approach could also be defined as constructive learning. For example, the study featuring mobile phones in English language classrooms by researchers such as Rahamat, Shah, Din, and Aziz (2011), and Azar \& Nasiri (2014). Based on their findings, the results prove that the use of mobile learning (MALL) in class benefits students by motivating their learning attitude and enhancing their learning experience.

The concept of VR can be traced back to the mid-1960s which allows the user to perceive the virtual world as if it is felt and acted realistically (Sutherland, 1965). Hundreds of researchers started to explore the effects and applications of this technology and have produced various scientific papers for the last 20 years. According to Singhal, Bagga, Goyal, and Saxena (2012), VR technology grabbed the attention of the public because it allows users to interact with real and virtual objects, providing learning through experience as well as increasing user attention and motivation at the same time. There is evidence showing that VR application has been adapted throughout several educational sectors for early education and primary schools in teaching the English language in other countries. It was proven that the exposure of VR applications helped improve students' motivation and more positive attitudes towards learning the English language. Each learner would demonstrate a positive attitude when the technology was easy and useful for them to learn. (Venkatesh, Morris, Davis \& Davis,
2003).

\subsection{Problem Statement}

When it comes to teaching with technology, there are pros and cons to it. Even though it does improve the students' motivation to learn, teachers must also consider the fact that students may be too distracted with the content that they sometimes would not be able to grasp the main ideas of the actual context. Moreover, even with the advancement of technology, there are still some students that are yet to own their own high-tech devices.

Even though VR could be considered a unique method in teaching students the English language, it may also cause problems to them. For example, it could be considered rather costly to some students who are not able to acquire it. Additionally, understanding technology such as digital innovations could even be a problem for teachers apart from the students. The lack of learning content was the main argument among teachers as VR was primarily designed for entertainment purposes. It has been considered to be quite a challenge for teachers to acquire technical skills when incorporating this in pedagogical planning. Thus, cognitive overload when using VR apps can be considered quite a challenge for an effective learning environment.

According to Becta (2004), the inaccessibility of ICT resources was not only because of the non-availability of hardware and software or other ICT materials, but also due to several factors such as poor resource organization, poor quality hardware or inappropriate software. Teachers also need to provide multiple teaching instructions for many different devices as each student may own different types of ICT resources.

\subsection{Research Objectives}

1) To find out University interns' perceptions on the use of ICT Techs (MALL, Gamification, and VR) in teaching English for secondary students during the Covid-19 Pandemic in Malaysia.

2) To investigate which of these ICT Techs (MALL, Gamification, and VR) would be most preferred by the University interns.

\subsection{Research Questions}

1) What are the University Interns' perceptions of ICT Techs (MALL, Gamification, and VR) application in teaching the English Language for secondary school students during this Covid-19 Pandemic in Malaysia?

2) Which ICT Techs (MALL, Gamification, and VR) would be most preferred by the Interns in enhancing English for secondary school students? 


\section{Literature Review}

\subsection{COVID-19 Pandemic, Outbreak Educational Sector and Students Online Learning in Saudi Arabia}

Muhammad Tanveer and Amiya Bhaumik from Lincoln University, Malaysia; Shafiqul Hassan from Prince Sultan University, Saudi Arabia; and Ikram Ul Haq from King Saud bin Abdul-Aziz University for Health Sciences, both were from Saudi Arabia, Saudi Arabia (2020); have conducted research on Saudi Arabia with regards to this recent and still ongoing Coronavirus pandemic outbreak that has caused worldwide emergencies, and impacted the educational system. The purpose of this study was to emphasize the results of Virtual learning classes among students from Saudi Arabia in the times of the Coronavirus outbreak. A total of 500 students participated in this study voluntarily. Of this total, 345 students originated from Saudi Arabia, and the rest of the participants were from China, Pakistan and India who studied in Saudi Universities. The authors use quantitative and qualitative methodology to analyse the outcome of this study. The findings of this study showed that teaching and learning through Virtual Classes was very challenging, especially for the teachers. First, the teachers had no basic knowledge on setting up a virtual classroom to communicate with students, and they faced challenges in preparing for lessons as well. Moreover, students had difficulties in understanding the materials given without guidance and faced problems in submitting assignments when they could not even meet the criteria without properly understanding the purpose. The authors stated that learning through a Virtual classroom was very stressful for students as it puts more pressure on them. Thus, it was suggested that teachers and parents engage directly via social platforms with regards to their students and children. In addition to that, both institutions and students should consider learning during this Coronavirus pandemic as a dual responsibility to utilize and explore other technology options to cope in terms of education and career path concerns.

\subsection{Designing Mobile Apps for English Vocabulary Learning}

Wang Bor-Tying (2017) conducted a pilot study to investigate effectiveness by through the development of mobile applications that include both English and Chinese descriptions to help enhance students' English vocabulary. A total of 30 students participated with a background of English level at CEF A2 level. The results showed that students were able to learn deeply in the real context and this method also increased their motivation, compared to using textbooks. Thus, the author stated that the mobile app promotes a student-centred teaching approach in which students work together to discuss and share their ideas with their peers. It helped enhance the students' vocabulary acquisition and improve their self-learning habits.

\subsection{Perception of the Usage of Mobile Assisted Language Learning (MALL) in English as a Second Language (ESL) Learning among Vocational College Students}

Wan Ummu Aiman Wan Azli, Parilah Mohd Shah and Maslawati Mohamad (2018) conducted a study to investigate the perceptions on the usage of MALL in English as a Second Language (ESL) among private vocational college students. There was a total of 100 students participating from KRU Academy vocational college. Based on the results, $60 \%$ of the participants agreed that using MALL gave them greater control over their tasks and most of them decided that this application was easy to use. $43 \%$ of them agreed that using MALL was much more accessible and beneficial in completing their tasks. Thus, the authors suggested applying the use of MALL as one of the teaching aids since it provides various activities for the students to explore regardless of time and place, as well as motivating them to engage with peers and teachers using the targeted language.

\subsection{Enhancing English Language Learners' Motivation through Online Games}

Nataliia V. Iaremenko (2017) conducted a study on how gamified learning brings a positive impact to motivate students in learning the English language. A total of 120 students from the National University of Life and Environmental Sciences of Ukraine in Kyiv was chosen. The findings showed that games had been proven to be motivating in terms of cognitive, emotional, and social aspects of players. The author suggested that teachers need to accept the fact that gamification could also become one of the critical technological tools to teach students in the language classroom because not only it helps increase students' motivation but also their participation in the learning process.

\subsection{Enhancement of Performance and Motivation through the Application of Digital Games in an English Language Class}

Saovapa Wichadee and Fasawang Pattanapichet (2018) conducted a study about how a digital game could impact students' learning performance and motivation. The targeted population was 2,645 students at a private university in Thailand. Based on the results gathered, gamified learning (Kahoot) produced more achievements from students and increased their learning motivation. The authors stated that the application of digital games can 
change the situation in the learning process from being dull and challenging to exciting and much easier to understand.

\subsection{The Effect of Virtual Reality on EFL Writing Performance}

Emrah Dolgunsöz, Gürkan Yıldırım, and Serkan Yıldırım (2018) conducted a study based on VR technologies to examine the effect it had on developing EFL writing skills. The researchers used the sequential exploratory mixed methodology which initially analysed qualitative data and following that, synchronized them with quantitative findings. A total of 24 EFL first-year students voluntarily participated in this study. Based on the results, majority of the participants felt that VR provides the most benefits on listening skills acquisition. The participants showed a slight improvement in writing skills only when they were given information with VR for writing purposes. Overall, the researchers stated that although VR does not affect learners' writing performance, it does make a difference to their long-term retention. Participants enjoyed the VR experience and found it surreal in terms of the learning environment. In the end, the researchers suggested further research to be done relating to the topic of different age groups and in other language skills such as speaking, listening, and reading.

\subsection{Students' Perception in Using Virtual Reality Device in English Classroom}

Siti Norzaimalina Abd Majid, Rosnani Ismail, Hafizoah Kassim, Asiah Kassim, and Aisyah Hanum Abu Bakar (2019) from University Malaya Pahang decided to conduct a study based on students' perception from using VR devices in English language classrooms. There were 137 students who volunteered to participate from a technical university in Malaysia. Based on the findings, the students gave a positive insight to the implementation of VR in the classroom. They found it to be a useful tool, flexible, and easier to use with clear and understandable instructions given. Moreover, most of the students agreed that using VR in learning English is an enjoyable experience and helped them to improve their reading skills as well. The participants in this study strongly recommended using VR as one of the learning tools for others because it brings various benefits in learning the English language in terms of usefulness and has instructions that are much easier to understand.

\subsection{The Gap}

Although technology has been successfully applied throughout education study in Malaysia, it is still difficult to sustain its success with the constant need for software and hardware upgrading. More money needs to be spent and invested in providing sufficient technical support. The Malaysia Education Blueprint of 2013 to 2015 provided software and 1Bestarinet for schools throughout the nation in a bid to compete with the rest of the world in this $21^{\text {st }}$ century computer literate generation. Still, it has yet to reach their goals up until 2018. This is because educators still prefer to use traditional methods of teaching.

Moreover, with the constant change of technology, most schools in Malaysia have yet to understand the true value of technology integration. For instance, Gamification and MALL have been practiced among the school educators in teaching secondary language, but not Virtual Reality. The reason is because of a lack of time, support, infrastructure, and many others. (Motaghian, Hassanzadeh, and Moghadam, 2013). Currently, four countries have started investing and using VR in their education, and this is in China, U.S.A, U.A.E, and France. These four countries have proven the success of virtual reality implementation into their educational sector.

Therefore, it is hoped that through this study a better understanding is given for educators to bring forward the innovative practices into English teaching by applying modern media platforms.

\section{Methodology}

A proposed sample was used for this study and the targeted population had a total of 63 participants. The distribution of this questionnaire was through social media platforms. The participants were given a set of questionnaires through the online Google Form link and all responses were collected anonymously.

The questionnaire was designed based on the five-point Likert-scale ranging from 1- Strongly Disagree, 2-Disagree, 3- Neutral, 4 -Agree, and 5 - Strongly Agree. Overall, there were 5 sections included in the questionnaire with a total of 21 questions. The first section of the questionnaire included participant personal information such as age, gender, and knowledge of the three technologies. The second, third, and fourth sections were based on the interns' perceptions for each of the technologies to be used to teach the English language during the Covid-19 pandemic outbreak. While the last section was based on their preference on which of these technologies (MALL, Gamification, and VR), they would choose to teach secondary school students.

\subsection{Pilot Test}

The questionnaire was piloted with the first 20 responses out of 63 interns. The data for the pilot study were run through SPSS to test the validity and reliability of each item. Each item was computed using the Cronbach Alpha in SPSS 23. For the items tested, .866 was generated as shown in Table 1, giving the conclusion that 
an $86 \%$ for internal consistency was obtained overall for the 19 items.

Table 1. Reliability Statistics

\begin{tabular}{|c|c|c|}
\hline $\begin{array}{c}\text { Cronbach's } \\
\text { Alpha }\end{array}$ & $\begin{array}{c}\text { Cronbach's Alpha Based on } \\
\text { Standardized Items }\end{array}$ & $\begin{array}{c}\text { N of } \\
\text { Items }\end{array}$ \\
\hline .866 & .862 & 19 \\
\hline
\end{tabular}

The results showed that the value of the piloted test was higher than $70 \%$. Hence, it was deemed absolute to justify that the items had a high reliability for further collection and analysis. Therefore, the data were considered reliable for analysis.

\section{Findings}

\subsection{Introduction}

This chapter aims to present the main findings of the data collected from the Management and Science University interns. These include the participants' responses to each question and their justifications at the end. The gender question was not asked nor included in the first part of the questionnaire since there were more females than the males among the participants. Thus, no questions based on gender were asked in the questionnaire.

\subsection{Main Findings}

This section presents the descriptive statistic of frequency for each item as presented categorically. The first part demonstrates the quantitative analysis of the data that would answer the first research question, (i) What is the University Interns' perception of ICT Techs (MALL, Gamification, and VR) in teaching the English Language for secondary school students during the Covid-19 Pandemic in Malaysia?

The second part presents the percentages that answer the second research question (ii) Which ICT Techs (MALL, Gamification, and VR) are most preferred by the Interns in enhancing English for secondary school students?
Table 2. Age

\begin{tabular}{|c|c|}
\hline Age & Total \\
\hline 22 & 29 \\
\hline 23 & 21 \\
\hline 25 & 2 \\
\hline 28 & 1 \\
\hline Total: & 63 \\
\hline
\end{tabular}

Table 2 shows the total of participants were divided according to their age groups. The table shows that majority of participants were 22 years old.

Table 3. Interns' knowledge and experience of the three ICT tools.

\begin{tabular}{|c|c|}
\hline $\begin{array}{c}\text { Have you ever used Gamification in } \\
\text { language teaching? }\end{array}$ & Frequencies \\
\hline YES & 45 \\
\hline NO & 18 \\
\hline $\begin{array}{c}\text { Have you ever used a MALL in language } \\
\text { teaching? }\end{array}$ & \\
\hline YES & 42 \\
\hline NO & 21 \\
\hline $\begin{array}{c}\text { Have you heard or read about Virtual } \\
\text { Reality? }\end{array}$ & \\
\hline YES & 55 \\
\hline NO & 8 \\
\hline
\end{tabular}

Table 3 indicates the frequencies for each question as responded by the participants. With an overall total of 63 responses collected, the majority of respondents had the experience of using both technologies (Gamification and MALL) in teaching languages during this pandemic outbreak in Malaysia and acknowledged the existence of VR.

\subsection{Research Question 1 - What is the University Interns' Perception of ICT Techs (MALL, Gamification, and VR) Application in Teaching the English Language for Secondary School Students during the Covid-19 Pandemic in Malaysia?}

For the second part of this questionnaire, respondents were to answer each question based on the 5-point Likert scale, where 1 - Strongly disagree, 2 - disagree, 3 Neutral, 4 - agree, and 5 - Strongly agree. 
Table 4. Total of frequencies for each question

\begin{tabular}{|c|c|c|c|c|c|}
\hline Questions & SD & $\mathbf{D}$ & $\mathbf{N}$ & A & SA \\
\hline Games are both fun and educational. & - & - & 6 & 32 & 25 \\
\hline Games should be given a special role in the foreign language teaching syllabus. & - & 1 & 1 & 27 & 34 \\
\hline A game-based learning approach is essential to train future teachers. & - & - & 2 & 33 & 28 \\
\hline Games are adaptable for different levels of knowledge. & - & - & 1 & 34 & 28 \\
\hline Games can be useful in stimulating learners’ language acquisition. & - & - & - & 21 & 42 \\
\hline The utilization of MALL technologies increases students' motivation for language learning. & - & - & - & 21 & 42 \\
\hline $\begin{array}{c}\text { Applications such as WhatsApp, Telegram, and Facebook provide opportunities to use English } \\
\text { language without the limitation of time and space. }\end{array}$ & - & 2 & 2 & 16 & 43 \\
\hline MALL systems could increase the quality of lessons. & - & 3 & 4 & 15 & 41 \\
\hline $\begin{array}{l}\text { M-learning technologies can be used as a supplement to language learning and teaching at all } \\
\text { levels of education. }\end{array}$ & - & - & 3 & 13 & 47 \\
\hline MALL applications can generate real-world, communicative tasks for Language learners. & - & - & 2 & 18 & 43 \\
\hline VR would add fun to the teaching process. & - & 1 & 1 & 25 & 36 \\
\hline VR is attractive and would motivate the learners. & - & - & 1 & 22 & 40 \\
\hline VR presents a fun and challenging way to engage students in language learning. & - & - & - & 33 & 30 \\
\hline VR should be considered as one of the teaching aids for language practice. & - & - & - & 43 & 20 \\
\hline VR can be considered as a realistic approach to language learning. & - & - & - & 40 & 23 \\
\hline
\end{tabular}

Such significant agreement was indicated in Table 4 . With a total of 63 respondents, the majority of participants showed a positive attitude towards the application of these three ICT techs (Gamification, MALL, and VR) for teaching the targeted language to students through a virtual classroom during the MCO period in Malaysia.

\subsection{Research Question 2 - Which ICT Techs (MALL, Gamification, and VR) would be most be Preferred by the University Interns in Enhancing English for Secondary School Students?}

This section demonstrates the results regarding frequency and percentage for the close-ended second research question (ii) Which ICT techs (Gamification, MALL, and VR) would be most preferred by the University Interns in enhancing English for secondary school students?

\section{Percentage}

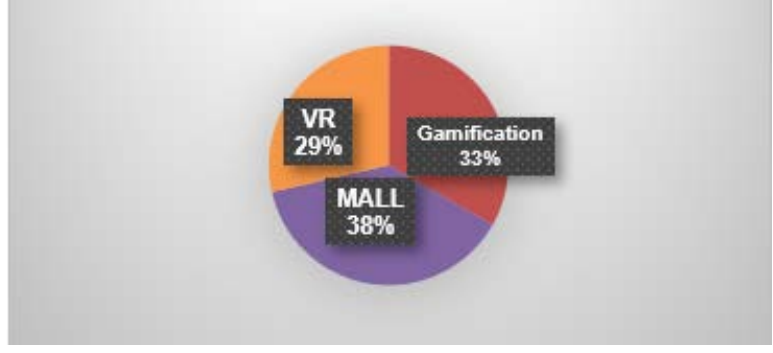

Figure 1. Percentages for three ICT Tools
Figure 1 shows the overall results of respondents with MALL having the highest percentage of $38 \%$, Gamification with 33\%, and VR with the lowest at $29 \%$.

\section{Discussion}

\subsection{Summary of Findings}

The findings implied that interns believed the importance of gamification to be adapted in teaching the English language among secondary school students during the Covid-19 Pandemic in Malaysia, as it could create a fun and enjoyable environment for students to learn.

"The fact that young students prefer to use computer games in acquiring new information should be expected.” - Prensky (2001)

Hence, the interns agreed that future teachers should be trained on the game-based learning methodology beforehand to prepare for the virtual classroom in engaging with students during the MCO period in Malaysia.

Furthermore, the interns' rated all the items positively as they understood that MALL had high potential in contributing to effective second language acquisition for secondary school students. As a recent development in mobile technology:

"It was becoming a practice trend in technology-enhanced language learning where teacher-student can learn and teach digitally anywhere and anytime.” - Şad \& Göktaş (2013)

It was emphasized among other researchers that 
language learning is beneficial if it were managed in systematic ways through mobile applications when teaching the targeted language during the MCO period due to Covid-19 in Malaysia.

"VR not only can change the way students learned but also exposed them to a simulated version of the reality which could be manipulated to suit the students’ learning needs.” - Yahaya (2007),

The data implied that the interns viewed VR technology as a fun and challenging way to engage students in the language learning process through a virtual classroom. As enjoyable and productive as it is, it could also present a more real-life learning environment for the students during the MCO period. And thus, creating a feeling of involvement among students.

\subsection{Comparison of Findings with Previous Studies}

A series of recent studies have indicated that the use of gamification in second language learning has brought a significant benefit not only in terms of enhancing the students' language learning process but also in terms of motivation as well.

"Gamification can give more exposure towards learning to students during this MCO as it adds fun educational learning” (S1)

The finding of this study runs parallel with one of the related literature reviews, Nataliia V. Iaremenko (2017), which stated that:

"The application of game elements into education makes it more relaxed, fun and comfortable for the students to learn."

This can be agreed upon for catering to the needs of the new generation, that the key to successful technology integration in teaching the targeted language during the MCO period in Malaysia would be the efficient use of digital tools for better student engagement as appropriate to the tasks.

A further novel finding was that mobile learning applications have been increasingly used by teachers to engage with students for language learning since the start of the MCO period. Several pieces of evidence have suggested that MALL does provide students with potential benefits in learning a second language, creating a more effective process learning-teaching through the virtual classroom setting. In line with a previous study by, Ornprapat Suwantarathip and Wiwat Orawiwatnakul (2015), mobile phones can create a pleasant learning environment and have a positive effect on learning.

"Students achieve better results in a positive learning environment during this pandemic outbreak period when they can connect with their peers virtually. M-learning can help enhance social integration among students with different learning needs and styles.” (S2)
The results of VR in data findings were equal to previous studies by researchers where the application of virtual reality in language learning had immense potential through immersive and exploratory learning for the students. apart from helping the students to understand the main idea of the learning topics, it also enabled them to process new knowledge.

"VR visualizations can be experienced in any language.” (S3)

Liang-Yi Chung (2012) stated that:

"The unique virtual environment of this application provides actual proactive learning and interactions that enable the students to engage proactively in the virtual world.”

\subsection{Arguments}

As this outbreak of the Covid-19 pandemic throughout the globe is still an ongoing situation, schools being a part of the education system have had with no option but to be closed in Malaysia. Following an announcement from the Ministry of Education, online learning was opted for to enable lessons to continue throughout the MCO period in Malaysia, and teachers are expected to explore technological tools and be creative when conducting lessons virtually. The challenges teachers had to face with this sudden digital demand were quite drastic in order to adapt to the new norm. It was not an easy task for most teachers in Malaysia to bear the responsibility of making sure the learning process went smoothly and efficiently.

Even so, students were more responsive and supportive when learning virtually from their respective homes during this MCO period. Previous studies showed that students found this experience to be unique and enjoyable. Students were motivated to engage through learning sessions either in group discussions or by participating in online debates.

Besides that, since technology has been a crucial part of education in this digital era, it has helped to ease the process of teaching and learning the targeted language. It is time for future teachers to rethink the idea of applying technology into teaching the English language among secondary school students, as it gives much more information than a textbook can provide. Besides that, technology could help by supporting students in their ability to learn and enhance their language skills and benefit the teacher in meeting the students' needs in language learning settings. The positive effect from technology has offered numerous alternatives for teachers to create a teaching and learning process in a more fun and productive environment for students.

Nonetheless, the present study confirmed that gamification produced real-world experience according to scaffolding concepts, MALL helped deliver essential resources with easy access anytime and anywhere, while 
Virtual Reality enabled the students to explore and interact through different types of social skills and actions. These introduced possible confounding factors in developing students' creativity that provided them with an appealing and enjoyable different style to study the second language.

"Language teachers should explore other technological-based lesson materials that could support students to enhance their language skills during this MCO period.” Pourhossein Gilakjani, and Sabouri, (2017)

"E-learning would give students better control over their own learning progress.” Dr. Abdelhak (2019)

\subsection{Conclusion}

\subsubsection{Suggestions}

When it comes to choosing a game during the MCO period while having to practice social distancing, teachers should consider the fact that students learn best when they interact with peers, while at the same time competing with one another, as it helps to boost their motivation and participation. A teacher should also consider the purpose of a game, the level, the number of students, equipment, materials, and time management to conduct a game-based approach when choosing a game that would best suit the students' needs in the language learning process.

"To maintain the students' motivation during Pandemic outbreak, it is recommended for teachers to use of many various strategies” Dörnyei (2001).

It was also recommended for future studies that an investigation of how English language teachers could accomplish blended learning lessons through the use of MALL depending on the objectives of a lesson. Interviews and observational assessments were highly advised for future research to test the use of mobile devices in second language learning among secondary school students.

Even though VR does help in developing students learning performances, there are not many applications designated for secondary school students targeted in teaching English language. Therefore, further analysis and experiments for this technology to be used in secondary school are strongly recommended for future teachers in the educational sector to understand how these gadgets can be utilised by language teachers and students to suit their needs during this ongoing outbreak pandemic situations.

\subsubsection{Conclusion}

The true purpose of this study was to determine which ICT techs (MALL, Gamification, and VR) would be most preferred by teachers to teach and improve secondary school students a targeted language. Since the Ministry of Education had announced the closure of schools all throughout the cities and countries in Malaysia, this had impacted most on education systems, especially teachers. Underprivileged students would face difficulties in accessing educational resources outside of education centres (UNESCO, 2020). This would lead teachers getting restless to adapt to their day-to-day job when planning and conducting the lessons virtually.

Even so, learning from the comfort of their own homes gives the students a sense of purpose during the MCO period of this Covid-19 pandemic outbreak. It creates a positive environment, experience, and opportunity in establishing the targeted language. Thus, teachers will need support and training for integrating technologies into teaching English language to secondary high school students. With the successful integration of these ICT tools, students would have the chance and possibility for effective and meaningful language enhancement.

Furthermore, this paper provides new insight and a better understanding of how these ICT techs (MALL, Gamification, and VR) should be used to improve students' language learning skills especially in developing their creativity and increasing their involvement to study the targeted language. To sum up, the results showed positive attitudes from the interns in increasing students' motivation to effectively learn the English language during the Covid-19 pandemic in Malaysia.

\section{REFERENCES}

[1] Ahmadi, D. (2018). The Use of Technology in English Language Learning: A Literature Review. International Journal of Research in English Education, 3(2), 115-125.

[2] Arikan, A. (2011). Effectiveness of using games in teaching grammar to young learners.

[3] Azar, A. S., \& Nasiri, H. (2014). Learners' attitudes toward the effectiveness of mobile assisted language learning (MALL) in L2 listening comprehension. Procedia-Social and Behavioral Sciences, 98, 1836-1843.

[4] Dolgunsöz, E., Yıldırım, G., \& Yıldırım, S. (2018). The effect of virtual reality on EFL writing performance.

[5] (n.d.). ENHANCING ENGLISH LANGUAGE LEARNERS' MOTIVATION THROUGH ONLINE GAMES.

[6] Gozcu, E., \& Caganaga, C. (2016). The importance of using games in EFL classrooms.

[7] Hashim, H. (2018, 5 17). Application of Technology in the Digital Era Education. International Journal of Research in Counseling and Education, 1(2), 1.

[8] Hashim, H., Md. Yunus, M., Amin Embi, M., \& Mohamed Ozir, N. (2017, 3 29). Mobile-assisted Language Learning (MALL) for ESL Learners: A Review of Affordances and Constraints. Sains Humanika, 9(1-5).

[9] Kassim, H. (2018). STUDENTS' PERCEPTION IN USING 
VIRTUAL REALITY DEVICE IN ENGLISH CLASSROOM.

[10] Rafail Prodani, Silvja Çobani, Jozef Bushati, and Aigars Andersons. (2020). An Assessment of the Factors that Influence the Use of Digital Technologies in Teaching: A case study. Universal Journal of Educational Research 8(4), 1453-1460.

[11] Vasileiadou, I., \& Makrina, Z. (2017, 11 7). Using Online Computer Games in the ELT Classroom: A Case Study. English Language Teaching, 10(12), 134.

[12] Wan Azli, W., Shah, P., \& Mohamad, M. (2018). Perception on the Usage of Mobile Assisted Language Learning (MALL) in English as a Second Language (ESL) Learning among Vocational College Students. Creative Education, 09(01), 84-98.

[13] Wang, B.-T. (2017). Designing Mobile Apps for English Vocabulary Learning. International Journal of Information and Education Technology, 7(4), 279-283.

[14] Wichadee, S., \& Pattanapichet, F. (n.d.). ENHANCEMENT OF PERFORMANCE AND MOTIVATION THROUGH APPLICATION OF DIGITAL GAMES IN AN ENGLISH LANGUAGE CLASS. 